\title{
Adaptation of Chinese New Year Tradition among Thai Chinese in Songkhla Province amidst Modernization
}

\author{
Buakaew Jureerat $^{1} \&$ Janjula Jiraporn ${ }^{1}$ \\ ${ }^{1}$ Faculty of Liberal Arts, Prince of Songkla University, Songkhla, Thailand \\ Correspondence: Buakaew Jureerat, Faculty of Liberal Arts, Prince of Songkla University, Songkhla, Thailand. \\ Tel: 66-74-28-6751. E-mail: jureeratana.k@psu.ac.th
}

\author{
Received: November 18, 2014 Accepted: December 22, 2014 Online Published: April 30, 2015 \\ doi:10.5539/ass.v11n12p144 URL: http://dx.doi.org/10.5539/ass.v11n12p144
}

\begin{abstract}
The objective of this study was to explore the adaptation of Chinese New Year tradition among Thai Chinese in Songkhla Province amidst modernization. The data of this qualitative study were collected through in-depth interviews with $30 \mathrm{key}$ informants who were Thai Chinese. The informants were divided into three groups of 10 people, consisting of young people aged $19-24$ years, working-age people $25-60$ year, and elderly people aged 61 years or more.

The results of the study revealed that most Thai Chinese in Songkhla Province have adapted the tradition of Chinese New Year in terms of offerings used in paying respect to spirits emphasizing on conveniences by buying them readymade because many people do not have time to prepare them. The rituals in paying respect to deities have changed from the past as well because they are not very strict in following the traditional way of doing it any more, especially, the practice concerning the auspicious time to do it but focus more on simplicity and convenience, and adapt it according to the changing situation in manpower and money power. As a result, they reduce the scale and complication due to the economic condition as fewer children can come back home from their workplace in far ways places, which make it inconvenient for them to travel back and join the New Year festivities. However, Thai Chinese in Songkhla Province still practice the tradition with the same procedure that has been passed down from generation to generation through telling, teaching, and practicing it. Consequently, they are proud of the identity of their ethnicity and pass it down continually so that it becomes a powerful way of life among Thai Chinese in Songkhla Province who will preserve it.
\end{abstract}

Keywords: adaptation, Chinese descendant community, Chinese New Year, Thai Chinese, social change

\section{Introduction}

Thailand is a multi-cultural society where many ethnic groups of people have settled: Thais, Thai Chinese, Muslim Melayu, westerners, etc. Thai society is open freely to information from all over the world, and as a result, advancement in communication technology flows into the country unceasingly as well as cultures from other countries worldwide. The cultural dynamics driven by globalization has led the country to cultural combination including emergence of new cultures as a result from hybridization, homogenization, and resistance. There is a cultural flow through five dimensions: ethnoscapes, which are migration and traveling; mediascapes; ideoscapes, which are beliefs and administration concepts; financescapes; and technoscapes (Natthawuthisit \& Suphamon, 2010). This is why each ethnic group has adopted cultures from inside and outside the region, but the extent of adoption depends on the cultural strength of the group.

Songkhla is a province where many foreigners have settled because it is situated in a location suitable of being a trading seaport in the past because it is convenient for trading ships to anchor as there is a deep waterway near the beach (The National Archives of Thailand, Phra Kalahom official Affairs, Rama IV, 1859; Krom Phraya Phanuphanthuwong Woradet, 1961). Chinese migrated to Songkhla in the final phase of the Ayutthaya Kingdom. When Songkhla became increasingly prosperous, more Chinese and other foreigners came to do business and live there (The Vachirayan Library, King Rama IV's Archive, 1860; Historical Records Volume 3, 1963). Chinese adapted themselves to Thais and Thai society. Moreover, they were very determined, patient, frugal, and could eventually buy land and build their houses permanently in Thailand. Some were married to Thais and changed from using Chinese surnames to Thai surnames. Nevertheless, they have earnestly preserved their traditions and cultures and continuously passed down their Chinese identity to their Thai Chinese children until 
now (Roy \& Andrews, 1999). This is evidenced by the rituals Thai Chinese perform in their traditions unceasingly until today.

Important Chinese traditions that Thai Chinese have continued the practice are for example, the Chinese New Year tradition, the Hungry Ghost Festivals, Chinese wedding, the Moon Festival, Ching Ming Festival, etc. These traditions reflect beliefs, thoughts, doings, values, attitudes, morals, customs, ceremonies, and traces of civilization. This corresponds with Suphap (1993) who notes that important characteristics of traditions are in the practice that people have believed and practiced for a long time until they become thoughts or doings that have been passed down from generation to generation and have influence on people to the present time. In this article, however, only the Chinese New Year tradition will be discussed since this tradition has been practiced by Thai Chinese in Songkhla for such a long time and Thai Chinese consider it the occasion when the last day of the year passes by and the New Year arrives.

According to the legend of Chinese New Year Festival, once there was a hardworking man who worked all year round with no holidays. If he had taken a day off, he would have had worried about his family because he was so poor. One day he went to see a monk and asked when the town would collapse so that he could escape from suffering from working hard; the monk answered when the stone lion in front of the temple coughed up blood. Later a butcher put a lot of pork blood on the mouth of that lion. When people saw it, they thought the lion coughed up the blood as the man told them. They were very frightened thinking that the town was going to collapse, and so they used sugar canes to support the doors of their houses. The following morning when they saw that the town did not collapse, they were so happy that they wanted to celebrate. Therefore, they took a day off, went to see each other to talk about it, and wished each other happiness, and of course, they took the opportunity to enjoy themselves, too. That day was one day after the end of the twelfth month and it was the first day of the waxing phase, and that was how the Chinese New Year began. Before the New Year festival comes, Chinese clean their house, repair the parts that need to be repaired, paint the fence and doors, and dust everything in the house because they believe that cleaning the house is to sweep away any ill-fortune. Then they decorate their houses and important places with lanterns. On the main door of the house, two door gods are placed on either side of the door to keep evil spirits from entering the house and causing troubles to people living in that house. One god is called "Yuchi Gong" and the other is "Qin Shubao" (Phakamat, 1980).

In addition to this, Chinese New Year Festival is an important time when Chinese pay respect to their ancestors because they believe that if they do not pay respect to their ancestors with correct ritual steps, their trading or work will not be successful. This festival is also an opportunity to see relatives and tighten relationships among them. Being grateful to their ancestors and reciprocate with loyalty is an identity of Chinese.

Because of the importance of Chinese New Year Festival, Thai Chinese have continued the practice of paying respect to their ancestors during the festival. However, the present social influence from outside has come to affect Songkhla society because it is open to globalization because Songkhla is a center of communication and tourism for the Southern part of Thailand, and thus, there are many visitors from other countries as well as from all over Thailand to Songkhla. It is very interesting to find out whether amidst modernization, the new generations of Thai Chinese in Songkhla still give importance to this tradition and continue to preserve it, and because many ethnic groups have traveled to and from Songkhla continually, various cultures have been passed down across the border. Another interesting issue is that if they still practice it, how they sustain this important tradition. The researchers, therefore, aim to explore to find the answers to offer the experience to other cultures that are being pressed for expulsion and become weak and prone to cultural assimilation. The other question is how the beliefs have been handed down to the younger generation.

\section{Definitions of Terms}

Adaptation refers to changes that take place due to cultural and social environments that affect the way of life among the Thai Chinese community in Songkhla.

Thai Chinese refers to offspring of overseas Chinese who migrated to settle in Songkhla Province from the reigns of King Rama I to King Rama V.

Social change refers to modernization due to influence of the Industrial Revolution that has caused consumerism in the age of globalization in Songkhla Province

\section{Objective}

To explore the adaptation of the Chinese New Year tradition among Thai Chinese in Songkhla Province amidst modernization. 


\section{Research Method}

This qualitative research employed in-depth interviews and participatory observations to collect data, and the research design is as follows.

1. Study areas-Thepha District, Hat Yai District, Na Thawi District, Ra Nod District, and Sadao District of Songkhla Province were selected. This is because they are areas where Chinese who faced problems in their home country migrated to make their living in the reign of King Rama III, and have since settled in Thailand where their descendants have become Thai Chinese who actively continue Chinese rituals in many Chinese customs and traditions.

2. Informants-A total of $30 \mathrm{key}$ informants were divided into three age groups of 10 people as follows. Young people aged $19-24$ years, working-age people $25-60$ years, and elderly people aged 61 years or more.

3. Data analysis-The data collected from related documents, in-depth interviews, and participatory observations were analyzed using phenomenological analysis applied by Ganjanapan (2010) who emphasizes a thinking process with movements for learning, creativity, reproduction, and adaptation of the Thai Chinese community in Songkhla Province under the changing social and natural environments. In addition, the data analysis of this study applied Na Thalang's concept of beliefs in traditions (1997), and Roy \& Andrews' adaptation theory (1999) in describing the adaptation of the Chinese New Year tradition among Thai Chinese in Songkhla Province amidst social modernization, and in presenting analytical descriptions.

\section{Results of the study}

\subsection{Importance of the Chinese New Year Tradition}

The Chinese New Year tradition is a tradition that Thai Chinese have practiced due to a belief that reciprocations to ancestors with loyalty, and they show their gratitude during Chinese New Year festival when family members who work in other faraway places come back home. Besides, it is an occasion to celebrate New Year together and to relax after a year of hard work.

Thai Chinese in Songkhla Province give importance to the Chinese New Year tradition by cleaning their houses, decorating them with lanterns, and Chinese calligraphy of auspicious characters pasted on their front door panels. New red clothing are prepared in advance as it is believed that red is an auspicious color. Two days before New Year's Day are spending days when Thai Chinese buy items to prepare for the day that they perform rituals of paying respect to gods or deities.

On the following day called "Sa Chap", an important day during Chinese New Year festival, Thai Chinese in Songkhla Province pay respect to gods or deities. It is believed that on the day they pay respect to gods and ask to be blessed for the New Year, they also pay respect to their ancestors to show gratitude and loyalty in return for their ancestors' support that has enabled them to be successful in their occupation. The ritual procedure of paying respect is as follows.

1. The paying respect ceremony in the morning is called "Po Lao Ia" which means paying respect to deities (deities refer to sacred spirits). Foods for the morning ritual consist of pork, duck, chicken, whiskey, tea, Che Chai (vegetables), mandarin oranges, and desserts. Paying respect can be performed from midnight until early morning.

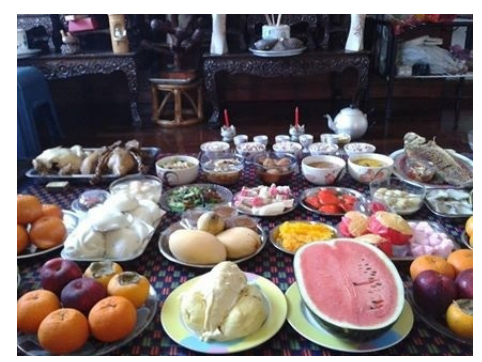

Figure 1. Paying Respect ceremony in the morning on Chinese New Year Day

(Photo taken by Asst. Prof. Janjula, Jiraporn on January 30, 2014)

2. The paying respect ceremony in the late morning is called "Pai Pe Bo", which means paying respect to parents, especially the deceased ones. This ritual must be performed before noon. Offerings used in the ritual consist of a set of meal complete with rice, savory dishes and desserts. 


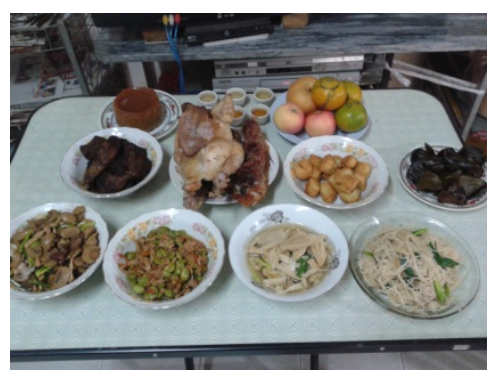

Figure 2. Paying Respect ceremony in the late morning on Chinese New Year Day

(Photo taken by Asst. Prof. Janjula, Jiraporn on January 30, 2014)

3. The paying respect ceremony in the afternoon is called "Pai Ho Hea Tee", which means paying respect to deceased ancestors or relatives. This ritual must be performed in the afternoon. There are more items than those used in the morning and late morning rituals. However, joss sticks and candles are the main items, and in addition to those used in the morning and late morning are Khanom Kheng, Khanom Thian, Khanom Thontai (these Khanom or desserts are made of sticky rice flour and sugar as the main ingredients), and silver and gold paper. Firecrackers must be lit. Some families perform this afternoon ritual with the late morning ritual (Kaemkhunthot, 2001).

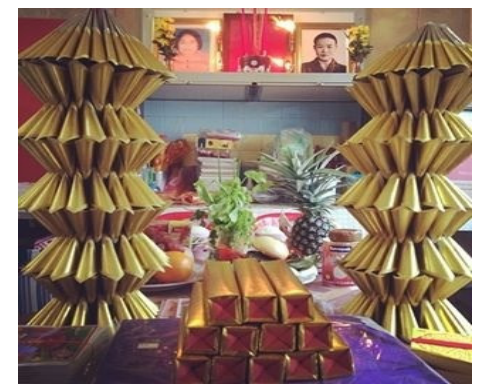

Figure 3. Paying Respect ceremony in the afternoon on Chinese New Year Day

(Photo taken by Asst. Prof. Janjula, Jiraporn on January 30, 2014)

In every ritual of paying respect, there must be the paying of respect to deities. For the ritual of paying respect to the guardian spirit, known as "Tee Chu Ia", the items used in paying respect are different from other rituals. They consist of five cups of tea, five 1-shot glasses of whiskey, five pairs of chopsticks, Sa Sae or Ngo Sae (three or five kinds of meat), other dishes, desserts, fruits, a pair of candles, three or five joss sticks, and silver and gold paper. This ceremony is an invitation to deities to come and receive the offerings and bless the family. When the joss sticks are burnt half way, silver and gold paper is burnt.

In addition, there is a paying respect ritual for stray spirits called "Ngow Hea Tee", which is performed from late afternoon to dusk. The ritual is performed outside the house, which can be on a mat or a table placed behind the house, if inconvenient, it can be in front of the house instead. The offerings include joss stick and candles, bamboo leaf tea, whiskey, Sa Sae or Ngo Sae (three or five kinds of meat), dried foods, rice, salt, vegetables, noodles, canned food, soda drinks, cigarettes, Khanom Thuai Fu (rice flour muffins), Khanom Kheng (sticky rice cake), steamed rice, soup, and other dishes of food, bowls and chopsticks, different kinds of fruits, silver paper, firecrackers, etc.

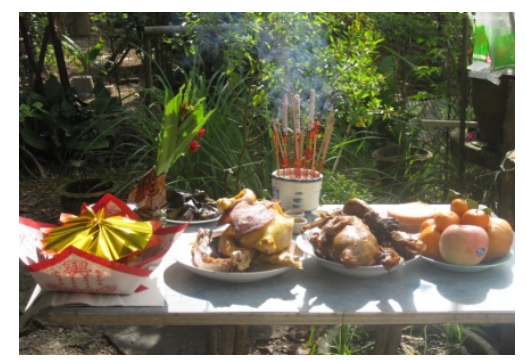

Figure 4. Paying Respect ritual for stray spirits on Chinese New Year Day

(Photo taken by Asst. Prof. Janjula, Jiraporn on January 30, 2014) 
When the paying respects ceremonies are over, the elderly or adults in the family give presents or money called "Tae Ia" to children so that they can have some money. Money is usually given in a red envelop called "Ang Pao". In the past, "Tae Ia money" is given to only children in the family. However, nowadays it is given to relatives, friends, and employees similar to bonuses. Besides, mandarin oranges are exchanged between families because Chinese regard mandarin oranges, called "Tai Kik" in Chinese, as an auspicious fruit with a good meaning that is good for recipients. For people who have debts, it is the day for them to pay the debts (Kaemkhuthot, 2001).

After the paying respect day, is the "Wan Thue" in Thai or "Chew Ik" day in Chinese or the first day of the New Year, which is an auspicious day when everyone has a holiday to celebrate. On this day, Thai Chinese abstain from sweeping the floor, quarrelling, killing, or hurting as it is believed that they are ill fates for one's life. When putting away utensils, one has to be extra careful not to make noise or drop the items. They abstain from using a knife or other sharp tools because it will cut off their luck. On this first day of the New Year, everyone wears beautiful new clothes because it is the day for the beginning of a new life. If they start with good things, life will be prosperous the whole year through. In the past, many Thai Chinese visited their relatives to wish them all the best but this tradition has changed as more and more people prefer visiting places. In the past, they also wished each other using their own dialects.

Therefore, the Chinese New Year tradition is very important for Thai Chinese in Songkhla Province as evidenced by the following statements made by some of the key informants. Mr. Phatthana-Amorn Phiphat (interviewed on November 16, 2013) said that the tradition has been practiced from the generation of his grandparents. It is the time to celebrate New Year together when all the children are home. Mrs. Chongwatthanaphaibun Wanna (interviewed on November 27, 2013) said that Chinese New Year is the time when everyone celebrates. Besides, there are statements made by several elderly Thai Chinese in Songkhla Province who confirm the importance of this tradition as follows.

"It is a tradition of celebrating Chinese New Year that has been practiced by many generations" (Mrs. Sae Lim Kanda, interviewed on October 28, 2013).

"At home we have celebrated Chinese New Year from the time of my grandparents" (Mrs. Chueaythong Phensri, interviewed on January 12, 2014).

"It's the homecoming day for our relatives and we can introduce them to each other and at the same time we can celebrate New Year together." (Mrs. Olankit Phornphan, interviewed on February 12, 2014).

It can be seen that the Thai Chinese elderly in Songkhla Province give importance to the Chinese New Year tradition that they have continued the practice from one generation to another at the same time as handed down the concept and beliefs to people who are middle-aged or working age, as can be seen from Miss Chewsuwan Rassamee (interviewed on January 18, 2014) who said that the Chinese New Year tradition is important for all Thai Chinese people because all family members get together to celebrate New Year. It's a good get together day for all relatives. However, now people go to work in different places so they do not do it as often as they used to. Mrs. Srisuk Pranee (interviewed on January 14, 2014) added to this viewpoint that it is to make merit when we pay respect to the guardian spirit and take a rest. It is good to be able to take 2-3 days off after working for the whole year long. We have a chance to spend some money after working for it. We should give some money to others, and we will get more later. In addition to these opinions, some young working-aged Thai Chinese in Songkhla Province also expressed similar opinions as follows.

"Chinese New Year is important because it is a Chinese festival that has been celebrated from our grandparent's time." (Mrs. Chaitrong Onsri, interviewed on March 10, 2014).

"Chinese New Year is still important for Thai Chinese who strongly believe in Chinese culture because this is a New Year celebration.” (Mrs. Uengthong Orawan, interviewed on January 15, 2014).

The above data collected from young working age people in Songkhla Province who still attach importance to the Chinese New Year tradition and can pass on this concept to the next generation of Thai Chinese. This is because they also adopt this concept and belief from their ancestors.

The new generation of Thai Chinese express their views that the Chinese New Year tradition is a Chinese culture that has existed for over a thousand years and can be practice anywhere to make Chinese feel like they have been back home to China. This is the same as Songkran Festival, which is a Thai culture of New Year celebration when family members get together and pay respect to the elderly, and the tradition has been passed down until the present. Chinese New Year Festival offers them a chance to meet Chinese from other countries and it is a get together among relatives that makes them feel warm in the heart. Miss Sirilawan Chayanit (interviewed on 
February 1, 2014) and Miss Sae Chee Kamolchat (interviewed on February 5, 2014) said that Chinese New Year is a good and important tradition because it is a get together for relatives, to have fun, and wear new outfits. Miss Ratiwisan Nanthika (interviewed on February 3, 2014) stated that Chinese New Year is important because we pay respect to a New Year but she does not like to go anywhere on Chinese New Year Day because it is hot and there are too many people. But she likes it because I get Ang Pao money, get to eat good food, and to meet relatives. Another informant is Miss Thertthatsanai Sasithon (interviewed on February 15, 2014) said that it's the time to pay respect to her ancestors and celebrate New Year. Her parents ask her to help prepare offerings and to join her relatives every year, and she likes it because there are a lot of good things and fun. Miss Yongyutthikun Supawee (interviewed on February 20,2014) said that it is to celebrate New Year, and she joins it every year to pay respect to deities, and ancestors while Miss Densuriyaphong Kasina (interviewed on January 19, 2014) said that her family practice this traditions. She helps her mother who tells her what to do and how to do it. In addition, the following are statements by the new generation who have similar views.

"I pay respect to my ancestors, get to each food after the ritual, and get Ang Pao. I feel good practicing the tradition so I do it every year." (Miss Laopreecha Thitiporn, interviewed on January 20, 2014).

"It's a good festival because I get Ang Pao from my elder relatives, light firecrackers and firework." (Miss Ang Chalita, interviewed on December 20, 2013).

"I get together with my relative; I get Ang Pao, and eat special food, and go out with my relatives." (Miss Areesantichai Yanisa, interviewed on December 23, 2013).

"I've seen my parents do it for so many years, and every family of my relatives celebrates it. Children get new outfits, something delicious to eat; get Ang Pao, and get to go out." (Miss Chamnanmueang Chalita, interviewed on December 27, 2013).

"It's a get together day for relatives and I get to eat delicious food. It means I get to pay respect to celebrate Chinese New Year." (Miss Chaitrong Natcha, interviewed on December 9, 2013).

It can be concluded from the interviews that Thai Chinese of the new generation see the importance of the tradition because it is New Year in Chinese culture that older people practice every year. Young people see it, participate in paying respect to deities, get new clothes, and Ang Pao, have an opportunity to see relatives and have special foods on the important day. The new generation receives good things from the Chinese New Year tradition and therefore, has good attitudes towards it.

\subsection{Inheriting the Chinese New Year Tradition}

Descendants of Chinese who, in the past, traveled over the sea to settle in Songkhla Province have become Thai Chinese in Songkhla who continue handing down the concept and beliefs by trying to tell their own stories to their children so that they can also continue the practice. This is how Chinese instill in their children the tradition of Chinese New Year. They show their children what and how to do things related to the tradition by allowing children to help prepare offerings used in paying respect. Family members participate in the preparation activities according to their ability. Chinese New Year Day is the day that relatives get together and the day that people have a chance to meet relatives from other districts and provinces to talk and to have meal together. Sometimes they travel to visit different places together to tighten their relationships. Adults give Ang Pao to children, which makes both children and adults happy; everybody is there together (Mrs. Sae Lim Kanda, interviewed on October 28, 2013). In organizing the paying respect, she teaches mainly her eldest daughter while the younger ones also help every year. She assigns everyone to do something because it is an important festival. Children are willing to help because they expect to get more Ang Pao when they do something good (Mrs. Chongwatthanaphaibun Wanna interviewed on November 27, 2014). In addition to this, Thai Chinese in Songkhla Province who are senior citizens speak in the same way as follows.

"In the past, their mother taught them to prepare offerings by helping to cook different dishes and desserts such as Khanom Kheng (sticky rice cake). Children help mill the flour. They also join in the paying respect ceremonies every year." (Mr. Phatthana-Amorn Phiphat, interviewed November 16, 2013).

"Chinese New Year is the only Chinese traditional festival that our family still practices, so it is an important annual festival for us. We don't practice other Chinese traditions anymore." (Mrs. Chueaythoung Phensri, interviews on January 12, 2014).

"I invite all my children and grandchildren to join the celebration every year and I assign each of them to do something, especially my eldest daughter and eldest granddaughter. I try to transfer how to do things by explaining while doing, demonstrating, and letting them do it. But people nowadays don't have time and are less 
patient, so most of them buy everything because it is much more convenient." (Mrs. Olankit Phonphan, interviewed on February 7, 2014).

From the interviews above, it can be seen that transferring the Chinese New Year tradition is carried out by telling how to do it, showing how to do it, and allowing participation in doing it repeatedly every year. This can enable the younger generation to absorb and to do it correctly, and to be able to replace their parents in practicing the tradition it when the parents are old.

It is the responsibility of the middle-aged Thai Chinese in Songkhla Province to inherit the Chinese New Year tradition because it is the time when they are ready to hand it down to the new generation after they have seen their grandmother and their mother do it from the time they were young. Everyone participates in it every year, has helped in preparing it, and has seen all the steps and now the legacy is passed on to them to carry on. It can be said that they have absorbed the tradition since they were children (Mrs. Chaitrong Onsri, interviewed on March 10, 2014). Mrs. Charoenthawon Churairat (interviewed on February 5, 2014), said that she has inherited the practice from her father. She has participated in the rituals of paying respect to her ancestors since she was very young, as soon as she could remember things. She said that after the rituals, the food was not consumed only in the family but it was also given to neighbors and friends. Every year her family uses about 10 ducks and chickens to give others, too, because it is only once a year and it is to tighten the relationships. Her father has done it this way and she does it the same way. Similar accounts that were given by other informants are as follows.

"I've seen my parents do it since I was young. My grandparents did the same things. They tell us to help preparing things for the event. In my family, my eldest sister knows the best and she inherits it while I and my younger sisters and brothers are only helpers." (Miss Chewsuwan Rassamee, interviewed on January 18, 2014).

"I pass it on to the next generation by doing it for them to watch, and they must join the tradition every year. I think the Chinese New Year tradition will probably stay on forever because it's an important festival and it's Chinese New Year. Another reason is that now it is convenient to buy items of offerings and all the foods are readymade. I think, in the future when I can no longer do it, my children will do it for sure because they have seen it and absorbed it since they were very young." (Mrs. Chaitrong Onsri, interviewed on March 10, 2014).

The above statements from the interviews reflect that Thai Chinese in Songkhla Province who are in their senior years are successful in handing down the Chinese New Year tradition to the middle-aged generation who have practiced it continuously and pass it on to the new generation who have good attitudes towards the tradition. One young informant said that she learns the tradition from her family because her mother and grandmother do it every year at home, and she participates it every year except when she is tied up with very important business. Her mother transfers it to her by teaching, showing, and assigning her to do something such as folding silver and gold paper, buying offering items for paying respect, arranging items on plates, putting tea cups and whiskey glasses on the correct positions, burn the silver and gold paper, light firecrackers, etc. (Miss Chaitrong Natcha, interviewed on December 9, 2013). Another informant said that her grandmother and her aunt are the heads in arranging the items for paying respect, and she helps them with whatever they tell her to do but now she does not have much time to help (Miss Laopreecha Thitiphon, interviewed on January 10, 2014). Moreover, Miss Sirilawan Chayanit, interviewed on February 1, 2014, said that her grandmother does it with help from her uncle, father and mother, and they buy some items that her grandmother tells them to buy. Then they arrange the table for paying respect to their ancestors. In another family, an aunt is the head in arranging the items and other family members help to buy things (Miss Sae Chee Kamonchat, interviewed on February 5, 2014). Now her mother arranges the items for the rituals, and she does not know much about it but she could do it by following her mother's instructions (Miss Ang Chalita, interviewed on December 20, 2013). In addition to the above statements, there are some other statements that correspond with them as follows.

"My grandmother arranges the items and others help cook the food." (Miss Areesantichai Yanisa, interviewed on December 23, 2013).

"I inherit it from my mother who instructs me and teaches me to do what she wants me to do." (Miss Densuriyaphrom Kasina, interviewed on January 19, 2014).

"My mother tells me to help and she has done it ever since I was young. I follow her to the market, help her cook, and prepare everything. She always explains it to me." (Miss Ratiwisakun Nanthika, interviewed on February 3, 2014).

"I learn something from my mother because she tells me to help her to do things such as folding silver and gold paper, arranging the dishes on the table, etc." (Miss Thertthatsanai Sasithon, interviewed on February 15, 2014). 
"There are some things that I cannot do when I'm told; my mother tells me to do just a few things but I'm not good at it. But my mother doesn't scold me because it is an auspicious day, scolding is not allowed." (Miss Chamnanmueang Chalita, interviewed on December, 27, 2013).

"I'm not good at it but I know what we need to have and to do because I've always seen my mother do it." (Miss Yongyutwutthikun Supawee, interviewed in February 20, 2014).

The above data indicate that the young generation of Thai Chinese has good attitudes towards direct and indirect learning. They do it and learn to do it by practicing it little by little through time and they will be able to do it better in the future.

\subsection{Adaptation of the Chinese New Year Tradition amidst Social Change}

A borderless world of information and communication and the economy of Thailand that is affected by world economy have impacts on customs and traditions of ethnic groups, and the Chinese New Year tradition is no exception. The tradition has to adapt itself so that it can resist the social change as evidenced by the statements of some informants who are senior Thai Chinese in Songkhla Province that their children are now grown up, and work in different places and provinces. As a result, it is not convenient for them to travel back home for a get together during Chinese New Year Festival while some of their grandchildren have to go to school or have something important to do, thus, not everyone is present like it used to be (Mr. Phatthana-Amorn Phiphat, interviewed on November 16, 2013).

Nevertheless, this tradition probably will continue to exist because Thai Chinese place emphasis on customs and traditions, and the Chinese New Year tradition has existed for such a long time that people see its importance. The number of Thai Chinese families that still continue practice it, and the number of tourists coming to visit many districts in Songkhla Province during Chinese New Year Festival have increased every year and the size of the festival has also increased. This is because many people are interested in the festival, and it is because of advertisement made by the province (Mrs. Olankit Phonphan, interviewed on February 7, 2014).

Nonetheless, there are people who are not certain whether the tradition will continue to exist because each family has different opinions on it. However, Mrs. Chueaythong Phensri, interviewed on January 12, 2014, said that she would continue the practice because it is a good festival that makes people happy and celebrate New Year together. This is in agreement with most people who think that the tradition will continue to exist but with a few adaptations as follows.

1. Offerings to deities-The new generation places more emphasis on convenience. They buy readymade offerings, and this practice is different from the past. The types of offering items have also changed according to availability of the items. They buy food and most anything needed for the rituals from superstores (Mrs. Sae Lim Kanda, interviewed on October 28, 2013). Therefore, this tradition will continue to exist because Thai Chinese descendents practice it every year, and they have learned about it and have seen their parents and grandparents do it since they were children. However, there will be some changes depending on the new generation's conveniences. They will probably not cook chicken and pork themselves but buy them readymade or precooked like roasted pork instead of boiled pork. They will also buy some dishes from Chinese restaurants, and they will buy Khanom Kheng, and other Khanom, too (Mrs. Chongwatthanaphaibun Wanna, interviewed on November 27, 2013). Young people in Bangkok pay respect to deities on Chinese New Year day and buy everything they need because they have to work and have no time to prepare everything like people of the previous generation did before (Mr. Phatthana-Amorn Phiphat, interviewed on November 16, 2013).

2. Rituals in paying respect to deities-The rituals in paying respect to deities and ancestors have changed to be more simple, not very strict in terms of time. The new generation may do it on another day or at other time depending on the situation, manpower as well as money power based on their convenience because they have to work (Miss Ang Chalita, interviewed on December 20, 2013). We should continue the tradition but reduce it to a smaller scale and simplify it because everything is more expensive (Miss Chewsuwan Rassami, interviewed on January 18, 2014), and Miss Ratiwisawakun Nanthika, interviewed on February 3, 2014. Besides, we can choose simpler methods such as offerings that consist dishes that are cooked using a simple method or buy ready to eat food instead. We can replace boiled chicken with chicken cooked for a dish called Khao Man Kai, or Hainanese chicken rice; boiled pork with Trang style of roasted pork, etc. (Miss Chaitrong Natcha, interviewed on December 9, 2013).

3. The number of people-The number of people participating in the tradition will probably decrease because many Thai Chinese descendants in Songkhla go to work, study and live in other provinces, especially Bangkok making it inconvenient for them to return home to celebrate Chinese New Year. Thus, not everyone can come 
home but this tradition will continue because young people know how to do it as they have participated in the rituals and have seen their parents do it from the time when they were children. The difference is that now they do it where they live and may adapt some of the rituals to suit their way of life instead of coming back to Songkhla, and they probably do it in a smaller scale in their own small family (Miss Chamnanmueang Chalita, interviewed on December, 27, 2013).

It can be said that the Chinese New Year tradition has been practiced by elderly people who have handed it down to their children from the past until the present, and some practices have changed along the time according to social change that never ends.

\section{Discussion}

Chinese society in Songkhla Province has given importance to the Chinese New Year tradition continuously even though globalization, at the same time, has brought in cultures from outside to this region. Moreover, people in this society are open to cultures from outside as well. Therefore, to survive in such a situation, the Chinese New Year tradition has to be adapted to accommodate social change as follows.

1. The importance of the Chinese New Year tradition will continue to exist as long as Thai Chinese in Songkhla Province still have faith and believe that paying respect to deities and ancestors helps them and their families to be successful in their occupation, prosperous in their work, and have courage to overcome obstacles in life in addition to showing gratitude towards them. Actually, this is not only to show their gratitude towards deceased ancestors but also alive ones because Thai Chinese descendants believe that their ancestors have helped make them and their family happy all year, and New Year is the time to thank them. According to Confucius, to be grateful to ones' ancestors and to reciprocate with loyalty is the awareness that younger generations should have. This is in accordance with the concept of Ganjanapan (2010) that regards this tradition as comprising a thinking process with movements for learning, creativity, and reproduction of culture as well as adaptation of the Thai Chinese community in Songkhla Province. The researchers think that this tradition can be passed down to younger generations because overseas Chinese in Songkhla Province place emphasis on creating and instilling identity of being Chinese in their offspring. Furthermore, the Chinese New Year tradition is not only to pay respect to deities and ancestors but also for family and relatives to celebrate New Year together to tighten their relationships, which is suitable for Thai society nowadays where consumerism is a growing trend. The Chinese New Year Tradition can help reduce generation gap in Chinese society in Songkhla Province, which corresponds with Na Thalang (1997)'s concept of beliefs in traditions that beliefs are important for living and have influence on society. Moreover, they dictate how people behave, and when individuals believe in something, it can motivate them take action in response to the belief. Praphaphitthayakon et al. (1987) state that a belief is something that a society has practiced continuously for a long time that it becomes regulations and guidelines for practice while Atthakon (1977) specifies that beliefs can result in rituals that have been practiced continuously that they eventually become traditions.

Beliefs in ancestral spirits, deceased parents and grandparents, especially, that their spirits are still around to protect their children result in ancestor worship as the rituals of paying respect to ancestors during Chinese New Year Festival among Thai Chinese in Songkhla Province. They practice it because it gives them confidence, and in doing some creative work, inspiration is needed and such confidence is believed to help them to be successful. This is in agreement with Chongrakwong (1999) who believes that beliefs are useful and important for living as well as influential to society because it designates behavioral expressions of people in society.

As can be seen, these beliefs have become part of the way of life for Thai Chinese in Songkhla Province who teach and do it so that their children can gradually absorb and eventually do it themselves. The beliefs have certainly become traditions for Thai Chinese in Songkhla Province to practice together with their family, relatives, and friends, and this is valuable for the family institute as well as Thai society.

Inheriting the Chinese New Year tradition-It can be concluded from the field data that the inheritance of the Chinese New Year tradition has been practiced with certain steps and the procedure has been deeply rooted and passed down verbally and repeatedly. "Teach, assign, do, be proud of the identity of our own ethnicity" has become the power of Thai Chinese in Songkhla Province that must be conserved and passed on because it is a phenomenon that makes the identity of Thai Chinese in Songkhla outstanding together with Songkhla Province. This is in line with Husserl (1954)'s concept in the book "The Crisis of European Sciences and Transcendental Phenomenology" that human experiences including imagination, dream, emotion, and feeling that have become human awareness. Thus, Thai Chinese in Songkhla Province have been instilled in themselves with the Chinese New Year Tradition that has been practiced and rooted down in the heart of everyone, which helps continue the inheritance to the following generations. 
Adaptation of the Chinese New Year Tradition among Thai Chinese in Songkhla Province in the modern world amidst ethnic diversity that enters freely among Thai Chinese in Songkhla Province who are open to cultures from outside as a result of globalization that can weaken culture of each ethnic group. According to Roy \& Andrews (1966), human, family, group, organization, and community constitute in a holistic adaptation system, which indicates that humans are able to think, to be conscious with awareness, and to consider efficiently in order to change themselves and their environments. This is the same as the Thai Chinese society in Songkhla Province who use their beliefs and faith in their gratitude towards their ancestors as encouragement and moral support to drive themselves and families towards success and as the core in changing and empower themselves in resisting cultures that come from outside continuously. They adapt the way they practice the Chinese New Year Tradition in accordance with social situations continuously so that it remains in the root of the strong Chinese culture in the mixed blood of Thai Chinese in Songkhla Province, and will continue to be an important tradition.

\section{Conclusion}

It can be concluded from the study that Thai Chinese in Songkhla Province give importance to gratitude towards their ancestors and reciprocate with loyalty in accordance with Confucius's concept. This belief has resulted in success in their occupation making them economically stable, and they consequently pass their belief on to the next generation by teaching, doing, and allowing participation in doing it. They do it little by little from the children are very young until they are old enough to carry it on by themselves. This maintains the Chinese New Year tradition as an important tradition that must be handed down to the younger generation continuously. This method of teaching is regarded as informal learning where learners absorb gratitude towards ancestors through a tradition. Even though it is now a globalization age, this tradition can still exist because it is adapted to correspond with social change. This indicates that Thai Chinese in Songkhla Province have unity in resisting the never-ending social change, and are able to carry on the Chinese New Year tradition so that it will continue its existence in Songkhla society.

\section{Recommendations}

1. The results of the study could be used as guidelines for preservation of other traditions among different ethnic groups that are fading away from society because of globalization.

2. Important traditions of other ethnic groups that are disappearing should be studied using the thinking process of informal learning, creativity and reproduction of such traditions in addition to the use of the adaptation of Thai Chinese in Songkhla Province under the context of social and natural environments as a case study.

\section{References}

Ang, C. (2013, December 20). Interviewed at No. 21, Monkhon Pracha 1 Road, Hat Yai District, Songkhla District. Age: 18.

Areesantichai, Y. (2013, December 23). Interviewed at No. 71/46-48 Pracha Rangsan Road, Hat Yai District, Songkhla Province. Age: 23.

Atthakorn, K. (1977). Folkloristics. Bangkok: Kurusapa Press.

Chaitrong, N. (2013, December 9). Interviewed at No. 153, Lam Phai Sub-district, Thepha District, Songkhla Province. Age: 19.

Chaitrong, O. (2014 March 10). Interviewed at No. 153, Lam Plai Sub-district, Thepha District, Songkhla Province. Age: 49.

Chamnanmueang, C. (2013, December 27). Interviewed at No. 95/35 Village No.10 Soi 55 Kanchanawanit Road, Mueang District, Songkhla Province. Age: 19.

Charoenthawon, C. (2014, February 5). Interviewed at No. 16/78 Sriphu Road, Na Thawi District, Songkhla Province. Age: 59.

Chewsuwan, R. (2014, January 18). Interviewed at No. 30 Soi 15 Petchkasem Road, Hat Yai District, Songkhla Province. Age: 58.

Chongrakwong, N. (1999). A study of Food Traditionally Served in a Cycle of Year by the Thais with Chinese Origin in Hat Yai Municipality, Hat Yai District, Songkhla Province (Master's thesis). Thaksin University.

Chongwatthanaphaibun, W. (2013, November 27). Interviewed at No. 83/193 Village No. 3, Soi 21 Kanchanawanit Road, Khohong Sub-district, Hat Yai District, Songkhla Province. Age: 65.

Chueaythong, P. (2014, January 12). Interviewed at No. 48 Soi 3 Rat Uthit Road, Hat Yai District, Songkhla 
Province. Age: 75.

Densuriyaphong, K. (2014, January 19). Interviewed at No. 20 Soi 9, Sakhon Mongkon 2 Road, Hat Yai District, Songkhla Province. Age 21.

Ganjanapan, A. (2010). Theory and Methodology of Cultural Research. Bangkok: Amarin.

Historical Records Volume 3 (Part 3). (1963). Bangkok: Kurusapa Press.

Husserl, E. (1954). The Crisis of European Sciences and Transcendental Phenomenology. Illinois: Northwestern U. P.

Kaemkhunthot, C. (n. d.). A Study of Customs throughout the Year among Thai Chinese Descendents in Phuket Municipality, Mueang District, Phuket Province (Master's thesis). Thaksin University.

Krom Phraya Phanuphanthuwong Woradet. (1961). Chivivat. Bangkok: Kurusapa Press.

Laopreecha, T. (2014, January 20). Interviewed at No. 163 Saeng Chan Road, Hat Yai District, Songkhla Province. Age: 20.

Na Thalang, E. (1997). Folk Wisdom in the Four Regions. Nonthaburi: Sukhothai Thammathirat Open University.

National Archives of Thailand. (1859). Phra Kalahom official Affairs (Rama IV, Vol. 17).

Natthawuthisit, K. \& Suphamon, C. (2010). Promotion of Economic Added Value with Cultural Capital. Research Report. Bangkok: Sasin Graduate Institute of Business Administration, Chulalongkorn University.

Olankit, P. (2014, February 12). Interviewed at No. 472/6 Kopkun Uthit 4, Phang La Sub-district, Sadao District, Songkhla Province. Age: 72.

Phakamat, O. (1980). Chinese New Year Festival in Traditions on Phuket Island. Phuket: Phuket Teacher College.

Phatthana-Amorn, P. (2013, November 16). Interviewed at No. 153 Village No.1, Lam Plai Sub-district, Thepha District, Songkhla Province. Age: 76.

Prapapitayakorn, P. (1987). Language and Culture. Bangkok: Aksorn Charoen Tat ACT Co., Ltd.

Ratiwisakun, N. (2014, February 3). 40 Soi 6/2, Petchkasem Road, Hat Yai District, Songkhla Province. Age: 19.

Roy, S. C., \& Andrews, H. A. (1999). The Roy's Adaptation Model. Connecticut: Appleton \& Lange.

Sae Chee, K. (2014, February 5). Interviewed at No.156/12 Village No. 4, Soi Ratbamrung, Niphat Songkhro 1, Khlong Hae Sub-district, Hat Yai District, Songkhla Province. Age: 20.

Sae Lim, K. (2013, October 28). Interviewed at No. 182/19, Village No. 1, Khuan Lang Sub-district, Hat Yai District, Songkhla Province. Age: 74.

Sirilawan, C. (2014, February 1). Interviewed at No. 5, Lamai Songkhro Road, Hat Yai District, Songkhla Province. Age: 19.

Srisuk, P. (2014, January 14). Interviewed at Ranot Market, Ranot District, Songkhla Province. Age: 64.

Suphap, S. (1993). Thai Society and Culture. Bangkok: Thai Watana Panich Press.

Thertthatsanai, S. (2014, February 15). Interviewed at No 7, Village No. 5 Soi Khuan Sato 2, Kanchanawanit Road, Phangla Sub-district, Sadao District, Songkhla Province. Age: 19.

Uengthong, O. (2014, January 15). Interviewed at No 218/3, Hat Yai District, Songkhla Province. Age: 57.

Vachirayan Library. (1860). King Rama IV's Archive (No. 114).

Yongyutthikun, S. (2014, February 20). Interviewed at No. 31, Thetsaban 4 Road, Phatong Sub-district, Hat Yai District, Songkhla Province. Age: 22.

\section{Copyrights}

Copyright for this article is retained by the author(s), with first publication rights granted to the journal.

This is an open-access article distributed under the terms and conditions of the Creative Commons Attribution license (http://creativecommons.org/licenses/by/3.0/). 